\title{
Root Extracts (Gymnadenia orchidis Lindl) Facilitated Rapid Synthesis of Fluorescent Silver Nanoparticles (Ag-NPs) for Various Biological Applications
}

\author{
Shilpi Show, Chetana Ghosal, Brajadulal Chattopadhyay* \\ Department of Physics, Jadavpur University, Kolkata, India \\ Email: ^bdc_physics@yahoo.co.in
}

How to cite this paper: Show, S., Ghosal, C. and Chattopadhyay, B. (2017) Root Extracts (Gymnadenia orchidis Lindl) Facilitated Rapid Synthesis of Fluorescent Silver Nanoparticles (Ag-NPs) for Various Biological Applications. Journal of Biomaterials and Nanobiotechnology, 8, 109-124.

http://dx.doi.org/10.4236/jbnb.2017.81008

Received: December 7, 2016

Accepted: January 19, 2017

Published: January 22, 2017

Copyright $\odot 2017$ by authors and Scientific Research Publishing Inc. This work is licensed under the Creative Commons Attribution International License (CC BY 4.0).

http://creativecommons.org/licenses/by/4.0/

\begin{abstract}
One pot rapid and green bio-synthesis of stable fluorescent silver nanoparticles (Ag-NPs) from silver nitrate solution using root extract of Gymnadenia orchidis Lindlat at ambient temperature is demonstrated productively. Surface Plasmon resonance of the synthesized Ag-NPs was shown to occur at $439 \mathrm{~nm}$ and two sharp fluorescence peaks at 610 and $780 \mathrm{~nm}$ were observed. FTIR study publicized the presence of chemically functional groups in the root extract surrounding the Ag-NPs, acting as stabilizers. XRD and FESEM analysis revealed that Ag-NPs were face centred cubic structure being spherical in shape with an average particle size of $28 \pm 2 \mathrm{~nm}(\mathrm{n}=100)$. The stability of Ag-NPs in neutral $\mathrm{pH}$ environment was confirmed by Zeta Potential $(\zeta$ ) behaviour. The Ag-NPs showed superior antioxidant activity. The notable photo-catalytic activity of biosynthesized Ag-NPs attributed to the existence of some proteins, responsible for degradation of methylene blue dye. Furthermore, Ag-NPs were found to exhibit a significant antibacterial effect against gram positive Staphylococcus aureus (S. aureus) bacteria.
\end{abstract}

\section{Keywords}

Green Synthesis, Gymnadenia orchidis Lindl, Silver Nanoparticles, DPPH, Photo-Catalytic, Antibacterial

\section{Introduction}

Nanotechnology is a promising growing field in the area of interdisciplinary research work, having specialization as well as applications in biotechnology. The formation of silver nanomaterial or nanoparticles (NPs) is widely examined by different chemical and physical methodologies, but the tool involved in synthesis of NPs in a consistent 
way is an important characteristic of nanotechnology [1]. Green synthesis of NPs of novel metals, such as $\mathrm{Ag}, \mathrm{Au}, \mathrm{Pd}, \mathrm{Pt}$, etc., as well as metal \& nonmetal oxides such as silica nanoparticles ( $\mathrm{SiO}_{2}-\mathrm{NPs}$ ), alumina, zirconia, titanium, etc., using biological entities like plant extracts, bacteria, fungi, etc., shows considerable interest of research in last couple of years [2] [3]. The use of plant extracts in green synthesis of metal NPs shows its potential over microorganism because of easy to scale up, rapid, eco-friendly and cost effectiveness [2]. The Ag-NPs are being the most investigated nanomaterial because of its potential applications in various fields, including food, cosmetics, medicine, etc., and also realized as the new generation antimicrobial and antioxidant agents. Some recent reports dealt with the use of plants or parts of plants extract as good bio-reducing agent or in green-synthesis of the Ag-NPs have been well established, a few examples are Memecylon umbellatum [2], Hevea brasiliensis [4], Volvariella volvacea [5], Stevia rebaudiana [6], Trachyspermum ammi, Papaver somniferum [7], Syzygium aromaticum [8], Dillenia indica [9], Piper pedicellatum C.DC [10], Solanum lycopersicums [11] and Prosopis farcta [12].

Gymnadenia orchidis Lindlis, a Himalayan endemic medicinal orchid is found in Hindu Kush Himalaya range. Its occurrence is sub-alpine and alpine zones from 2800 4200 metre above from the sea level (IUCN, 2004). Other than Nepal Himalayas, it is found in the same altitudinal ranges of India, Pakistan, Bhutan and China also. This plant was identified by the Botanical Survey of India, as the Gymnadenia orchidis Lindl of the orchidaceous family (Accession No.: 0046 dated 26.09.2014. V. No. SHRC5/02/2012-Tech.-195). The powder root of this plant when mixed with water, forms a thick "Salep" which is traditionally used by the local people to get some relief against diabetes.

To the best of our knowledge, there has been no report where phytochemicals of Gymnadenia orchidis Lindl were utilized as bio-reducing agents in production of Ag-NPs. In the present study, we have demonstrated an easy green approach for the formation of Ag-NPs using root extract of Gymnadenia orchidis Lindl. The as-prepared Ag-NPs were categorized by several tools like UV-Vis spectroscopy, fluorescence spectrophotometer, X-ray diffractometer (XRD), Field Emission Scanning Electron Microscope (FESEM-EDAX), Fourier Transform Infrared Spectroscopy (FTIR), Thermal Gravimetric Analysis (TGA) and Zeta Potential from Dynamic Light Scattering (DLS). The antioxidant activity by DPPH assay of biosynthesized Ag-NPs was studied and compared with natural antioxidant activity of ascorbic acid. The photo-catalytic activity of Ag-NPs against methylene blue (MB) dye was also demonstrated. The antibacterial effect of the biosynthesized Ag-NPs against Staphylococcus aureus (S. aureus) was confirmed as well. The present protocol implies the room temperature (RT), cost efficient, facile and one-pot green synthesis of Ag-NPs and its possible applicability in different fields such as biomedical, water purification method [13], dye removal [14], etc.

\section{Materials and Methods}

\subsection{Materials}

All chemical used in the present study are of high purity. The analytical grade silver nitrate $\left(\mathrm{AgNO}_{3}\right)$ was purchased from Sigma-Aldrich and Methylene Blue (MB), 1,1-di- 
phenyl-2-picrylhydrazyl (DPPH) and Methanol $\left(\mathrm{CH}_{3} \mathrm{OH}\right)$ were obtained from Merck, Germany. All chemicals were used without further purifications. Gymnadenia orchidis Lindlplant roots were collected from local area of Nepal Himalayas (Darjeeling, West Bengal, India). Throughout the experiment, deionised (DI) water was used whenever necessary.

\subsection{Preparation of Plant Root Extract}

The root (inset of Figure 1(a)) of Gymnadenia orchidis Lindl was collected from the area of Nepal Himalayas (Darjeeling, West Bengal, India) and washed thoroughly with DI-water several times to remove unwanted entities from it. Afterwards, $5 \mathrm{~g}$ of root slices was pasted homogeneously using mortar and pestle. Then, the pasted root was added to $100 \mathrm{ml}$ DI-water and boiled for $10 \mathrm{~min}$ followed by filtration through filter paper having diameter of $0.02 \mu \mathrm{m}$.
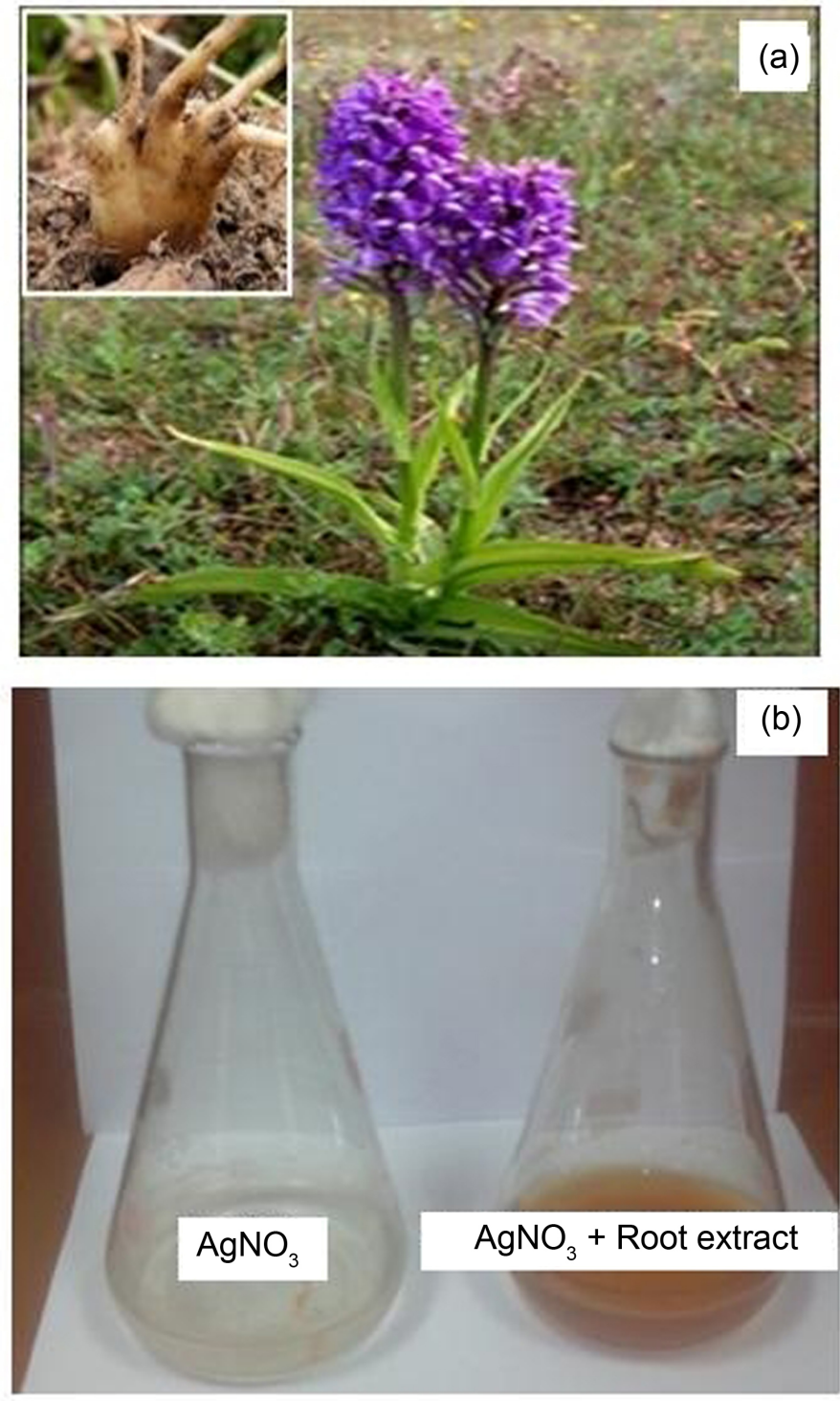

Figure 1. The photograph of (a) Gymnadenia orchidis Lindlplant, (b) Gymnadenia orchidis Lindlroots extract treated $\mathrm{AgNO}_{3}$ solution. 


\subsection{Biosynthesis of Ag-NPs}

Aqueous silver nitrate $\left(\mathrm{AgNO}_{3}\right)$ solution $(0.1 \mathrm{mM})$ was prepared as precursor for the synthesis of Ag-NPs. $10 \mathrm{ml}$ of Gymnadenia orchidis Lindlroots extract was added to 90 $\mathrm{ml}$ of precursor solution and kept at ambient temperature for $1 \mathrm{~h}$ to reduce the $\mathrm{Ag}^{+}$ ions. The colour of the reaction mixture turned colourless to dark brown solution [15] within $1 \mathrm{~h}$ due to the formation of Ag-NPs (Figure 1(b)). Gymnadenia orchidis Lindl roots extract might have some bio-reduction agents responsible for changing the colour of the reaction mixture.

\subsection{Characterization of Synthesised Ag-NPs}

Several tools were used to exemplify the final yields. The optical characterizations of Ag-NPs suspended in aqueous environment were performed with UV-Vis spectrophotometer (UV-3101PC, Shimadzu) and fluorescence spectrophotometer (Thermo scientific multiskan GO, SpectraMax M5 molecular device). The excitation wavelength $\left(\lambda_{\text {exc }}\right)$ to study the fluorescence characteristic of Ag-NPs was chosen at $390 \mathrm{~nm}$. XRD measurements was carried out on a Bruker, D8 Advance, X-ray diffractometer, operated at a voltage of $40 \mathrm{kV}$ and a current of $40 \mathrm{~mA}$ with $\mathrm{Cu} K_{\alpha}$ radiation $(\lambda=1.54 \AA)$. The surface morphology and composition of the bio-synthesized Ag-NPs were investigated by Field Emission Scanning Electron Microscopy (FE-SEM, FEI INSPECT F50) equipped with Energy dispersive spectrometer (EDAX, Bruker System). Fourier Transform Infrared Spectroscopy (FTIR-8700, Shimadzu) was employed to identify the types of the functional groups present in the Ag-NPs. The Ag-NPs powder was dried and crushed with $\mathrm{KBr}(1 \mathrm{wt} \%)$ to form pellet for receiving of FT-IR spectrum with a resolution of $4 \mathrm{~cm}^{-1}$. The thermal stability of Ag-NPs was observed by determining the weight loss of the sample against elevated temperature in TGA/SDTA $851{ }^{\mathrm{e}}$ Mettler Toledo thermal analyzer system. The synthesized Ag-NPs powder was disseminated in deionized water and the Zeta potential was estimated using DLS (Zeta Sizer, Nano ZS 90, Malvern) equipment. Each experiment was repeated several times $(n \geq 3)$ to get the average data.

\subsection{Antioxidant Activity}

The antioxidant activity of green synthesized Ag-NPs was determined by using the DPPH free radical scavenging assay as described by Molyneux et al. [16]. In particulars, $1.0 \mathrm{~g}$ of DPPH was dissolved in $100 \mathrm{ml}$ methanol. $3.0 \mathrm{ml}$ of test sample (either containing Ag-NPs or ascorbic acid) was mixed to $3.0 \mathrm{ml}$ of DPPH containing methanol and incubated for $30 \mathrm{~min}$ at RT. Four different concentrations of test sample were used for the study. The absorbance of the reaction mixture was noted at $517 \mathrm{~nm}$ using spectrophotometer. Ascorbic acid (a known innateantioxidant) was used as standard. The radical scavenging activity of Ag-NPs was measured by the percentage of inhibition of DPPH mixture discolouration using the following equation below:

$$
\% \text { of inhibition }=\frac{A_{\text {Blank }}-A_{\text {Sample }}}{A_{\text {Blank }}} \times 100
$$

where, $A_{\text {Blank }}$ and $A_{\text {Sample }}$ are the values of absorbance (Optical density) of the standard 
reaction mixture and the test mixture (standard reaction mixture containing Ag-NPs or ascorbic acid) respectively.

\subsection{Photo-Catalytic Activity}

Typically, $10 \mu \mathrm{M}$ MB dye solution was prepared as stock solution for the photo-catalytic activity of synthesized Ag-NPs. About $10 \mathrm{mg}$ of freeze dried Ag-NPs was added to a $40 \mathrm{ml}$ of $\mathrm{MB}$ dye solution in $100 \mathrm{ml}$ glass beaker. Only $\mathrm{MB}$ dye solution (without Ag-NPs) was taken for reference. The absorbance of the mixture was noted after thoroughly mixing the reaction solution by magnetic stirrer. At different time intervals, aliquots of $2-3 \mathrm{ml}$ suspension of the reaction mixture were filtered and used to estimate the photo-catalytic degradation of $\mathrm{MB}$ dye solution in presence of biosynthesized Ag-NPs. The change in absorbance spectrum due to the presence of Ag-NPs was consequently measured using UV-Vis spectrophotometer under UV light irradiation. Concentration of $\mathrm{MB}$ dye during degradation was calculated by the absorbance value at $663 \mathrm{~nm}$. Percentage of degradation of MB dye in presence of Ag-NPs was calculated by using the following formula:

$$
\% \text { of Decolourization }=\frac{\left(C_{0}-C\right)}{C_{0}} \times 100
$$

where $C_{0}$ is the initial concentration of $\mathrm{MB}$ dye solution and $C$ is the concentration of dye solution in presence of Ag-NPs in different time intervals.

\subsection{Antibacterial Activity}

The antibacterial activity of biosynthesized Ag-NPs was examined by observing the zone of inhibition against the growth of a gram positive bacterium $S$. aureus. Luria-Broth (LB) medium containing agar (2\%) was poured into Petridisc and allowed over night to get solidified. To the agar plate, $100 \mu \mathrm{l}$ of pre grown $S$. aureus bacterial cells $\left(1 \times 10^{8} \mathrm{CFU} / \mathrm{ml}\right)$ were spread on it and left at room temperature for at least 15 min. On the agar bed, 4 wells ( $7 \mathrm{~mm}$ of diameter) were made using the cork borer. One well was filled with $50 \mu \mathrm{l}$ sterile DI-water and the rest of three wells were filled with 50 $\mu \mathrm{l}$ of different concentration Ag-NPs solutions $(25 \mu \mathrm{g} / \mathrm{ml}, 50 \mu \mathrm{g} / \mathrm{ml}$ and $100 \mu \mathrm{g} / \mathrm{ml})$. Then the Petri plate was kept for incubation for $24 \mathrm{~h}$ at $37^{\circ} \mathrm{C}$. After the stipulated time period, the zone of inhibition produced at the different wells was observed. Two replicates were maintained for each concentration and the mean diameter value was expressed in millimetres.

\subsection{Statistical Analysis}

For each experimental set up, all the prepared samples were tested repeatedly. Each experiment was repeated at least three times. Data were presented as an average data with the S.D. where ever is possible.

\section{Results and Discussion}

\subsection{Optical Properties}

The development of the Ag-NPs was observed visually as the colour of the reaction 
mixture turned from a colour less to a dark brown solution [15] within $1 \mathrm{~h}$ as illustrated in Figure 1(b). Figure 2 are presents the UV-Vis spectraevolution of the $\mathrm{AgNO}_{3}$ solution $(1 \mathrm{mM})$, Gymnadenia orchidis Lindl roots water extract, the root extract mixed $\mathrm{AgNO}_{3}$ solution (after $1 \mathrm{~h}$ ) recorded at room temperature. No absorption peak was observed in $\mathrm{AgNO}_{3}$ solution and Gymnadenia orchidis Lindl roots water extract whereas in case of the root extract mixed $\mathrm{AgNO}_{3}$ solution, a broad visible absorption band ranging from 350 to $550 \mathrm{~nm}$ was observed. The wavelength corresponds to Surface Plasmon resonance (SPR) of as-prepared Ag-NPs, centeredat $\left(\lambda_{\max }\right) 439 \mathrm{~nm}$ (Figure 2(a)). Ag-NPs showed very interesting optical properties directly correlated with localised SPR having morphological dependence of the NPs. In conclusion no blue orredshift phenomenon of the absorption band of Ag-NPs was observed. This may indicate that no alteration of the size and shape (i.e., stable) of the Ag-NPs occur during incubation of bio-reduction process [17]. The room temperature fluorescence spectrum of the prepared Ag-NPs when excited at $390 \mathrm{~nm}$ is shown in Figure 2(b). Two sharp visible peaks at $610 \mathrm{~nm}$ (orange) and $780 \mathrm{~nm}$ (red) were observed. These emission peaks were due to the local field enhancement via coupling to the transverse and longitudinal SPR [18].

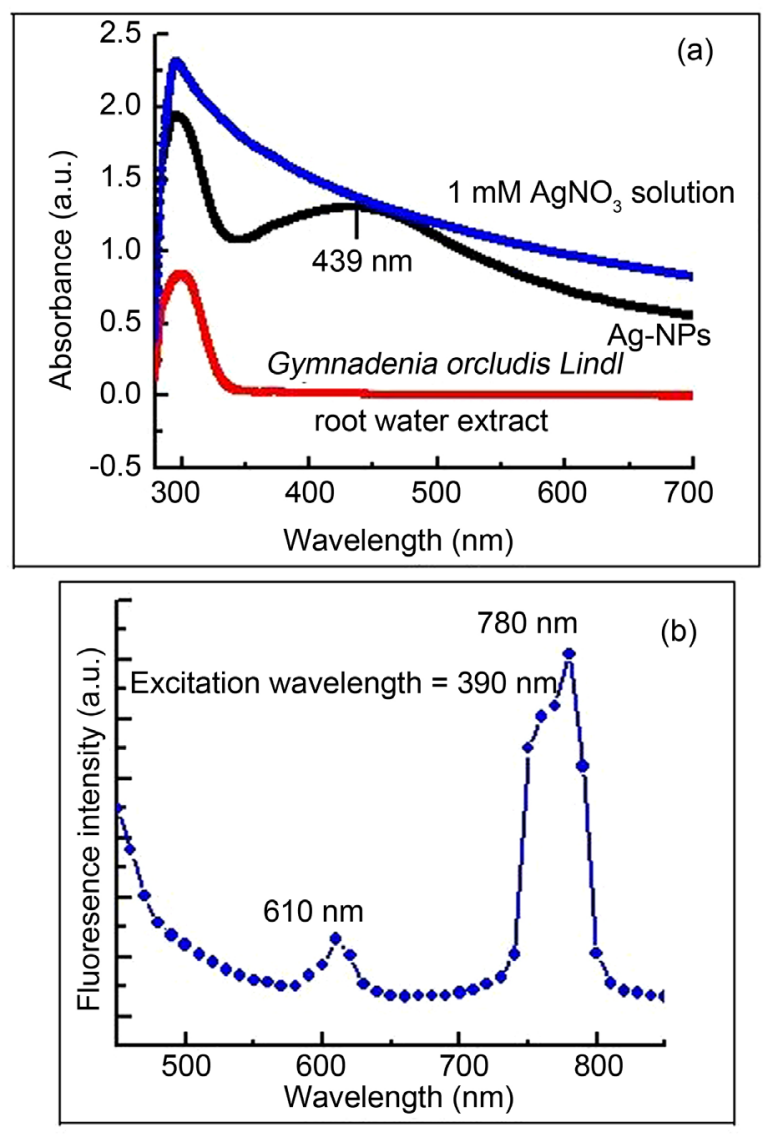

Figure 2. Spectroscopic analysis of the biosynthesized AgNPs dispersed in aqueous environment indicating (a) Absorbance spectrum and (b) Emission spectrum. The experimental Setup was repeated thrice and no significant errors were noted. 


\subsection{Morphological and Chemical Composition of Ag-NPs}

Figure 3 aindicates the FE-SEM image and EDAX spectra (inset of Figure 3(a)) of Ag-NPs formed by the interaction between Gymnadenia orchidis Lindlroots extract and $\mathrm{AgNO}_{3}$ solution. FE-SEM image confirmed the Ag-NPs were quiteuniform spherical in shape and polydisperse in nature. Few larger particles of Ag-NPs were appeared in the FE-SEM image which was due to NPs aggregation during synthesis process. This could lead to the variation in size of the particles. The histogram of the particle size distribution is shown in Figure 3(b). This illustrates that the maximum average particle is around $28 \pm 2 \mathrm{~nm}(\mathrm{n}=100)$. The EDAX analysis shown in the inset of Figure 3 are veals the strong signal at $3 \mathrm{keV}$ due to metallic nature of NPs [19].

\subsection{FTIR and XRD Studies}

FTIR spectrum (Figure 4(a)) was performed to confirm the chemically functional groups surrounded the Ag-NPs. It shows that the peak at $3325 \mathrm{~cm}^{-1}$ corresponds to water and O-H vibrational frequency. The small peak at $2916 \mathrm{~cm}^{-1}$ is characteristics of aldehydic $\mathrm{C}-\mathrm{H}$ stretching vibration. The peaks at $2352 \mathrm{~cm}^{-1}$ and $1620 \mathrm{~cm}^{-1}$ represents the asymmetric stretching of $\mathrm{C}-\mathrm{H}$ and carbonyl specific absorption $(\mathrm{C}=\mathrm{C})$ or amide $\mathrm{I}$ respectively. The peak at $1388 \mathrm{~cm}^{-1}$ corresponds of aromatic amine and nitro groups or amide II due to the $\mathrm{N}=\mathrm{O}$ bending vibrations. Peaks at $1153 \mathrm{~cm}^{-1}$ and $1029 \mathrm{~cm}^{-1}$ confirm the presence of $\mathrm{C}=\mathrm{O}$ and $\mathrm{C}-\mathrm{OH}$ stretching vibrations. FTIR study has confirmed that the carbonyl group from amino acid residue and peptide of proteins (amide I) both has the stronger ability to bind metals. It signifies that the protein may be responsible

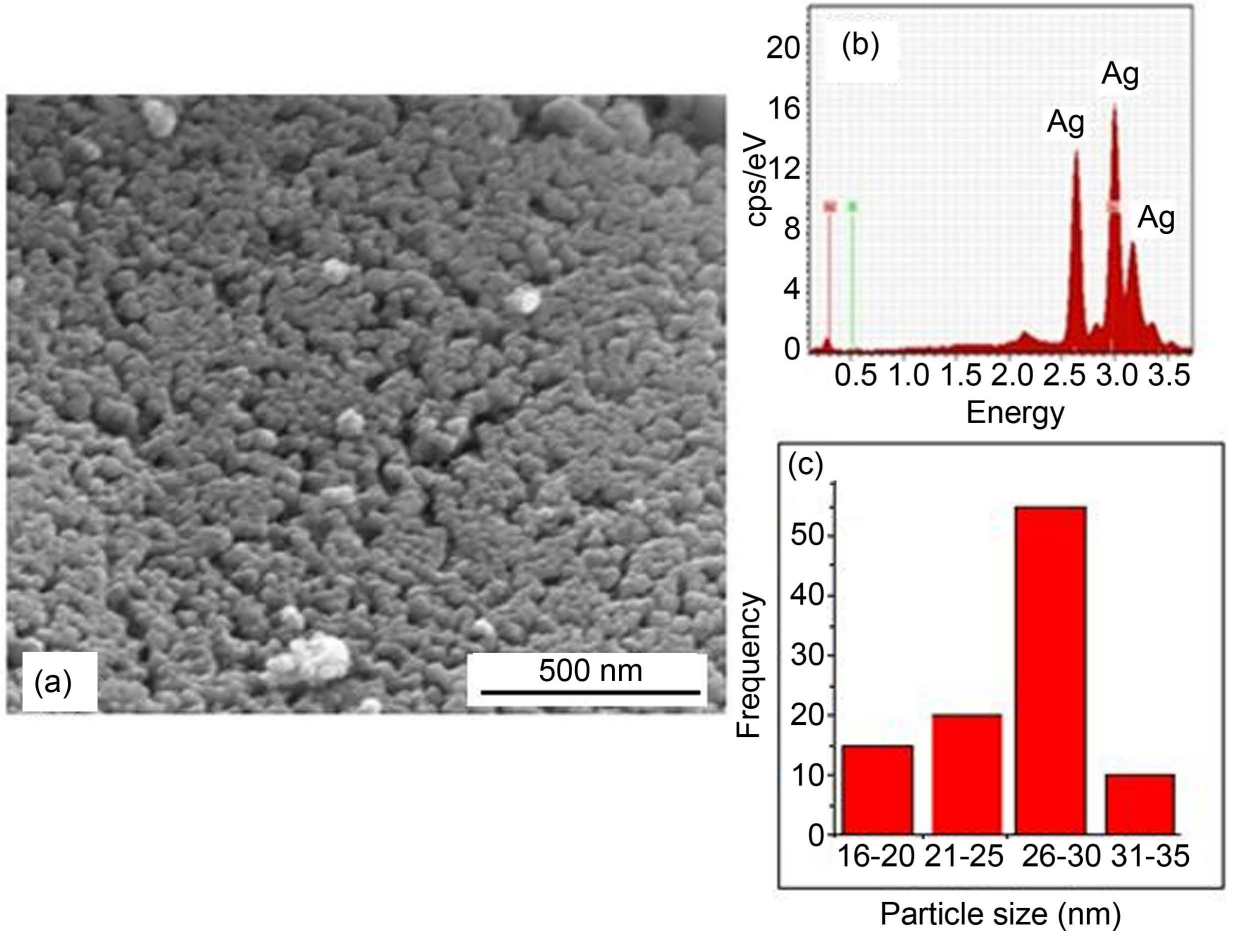

Figure 3. (a) FE-SEM image (Magnification: 200,000×) (b) EDAX spectrum and (c) Histogram showing the particle size distribution $(\mathrm{n}=100)$ of Ag-NPs formed by the interaction of Gymnadenia orchidis Lindl roots extract and $\mathrm{AgNO}_{3}$ solution. 

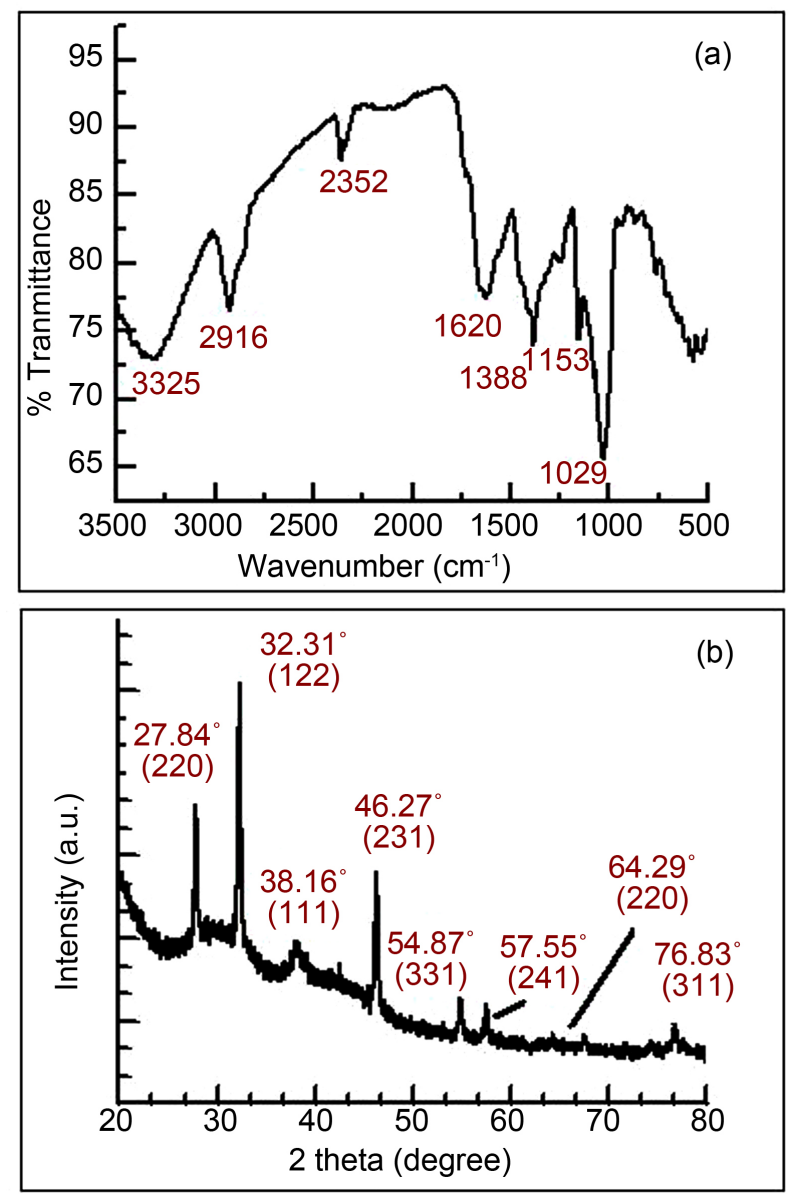

Figure 4. (a) FTIR spectrum and (b) XRD pattern of the green synthesized Ag-NPs. The experimental Setup was repeated thrice and no significant errors were noted.

for forming a surface layer on the metallic Ag-NPs that helps in stabilization of AgNPs.

The XRD pattern (Figure 4(b)) of biosynthesized Ag-NPs shows the peaks at $2 \theta=$ $38.2^{\circ}, 64.3^{\circ}$ and $76.8^{\circ}$ correspond to the diffraction due to (111), (220) and (311) planes respectively. It confirmed the crystalline face centred cubic structure [JCPDS, File No: 40738] of Ag-NPs. Apart from above three peaks several peaks were also observed. The unassigned diffraction peaks could be due to the crystallization of bio-organic phase that occurred on the surface of the biosynthesized Ag-NPs. The size of the synthesized Ag-NPs was calculated from X-ray line broadening using the Debye-Scherrer formula given as $\mathrm{D}=0.9 \lambda / \beta \cos \theta$, where $\mathrm{D}$ was the average size of crystalline $(\AA \hat{)}), \lambda$ was the

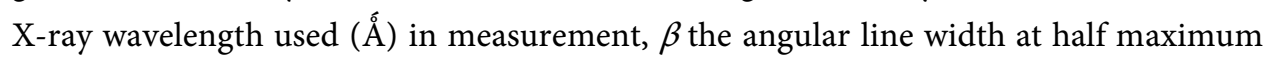
intensity and $\theta$ the Braggs angle (degrees). For (122) reflection plane the size of the Ag-NPs was calculated to be around $30 \mathrm{~nm}$ which was in good agreement with the data obtained from FE-SEM analysis.

\subsection{Thermal Properties of Ag-NPs}

Figure 5(a) indicates thermal properties of biosynthesized Ag-NPs measured from 

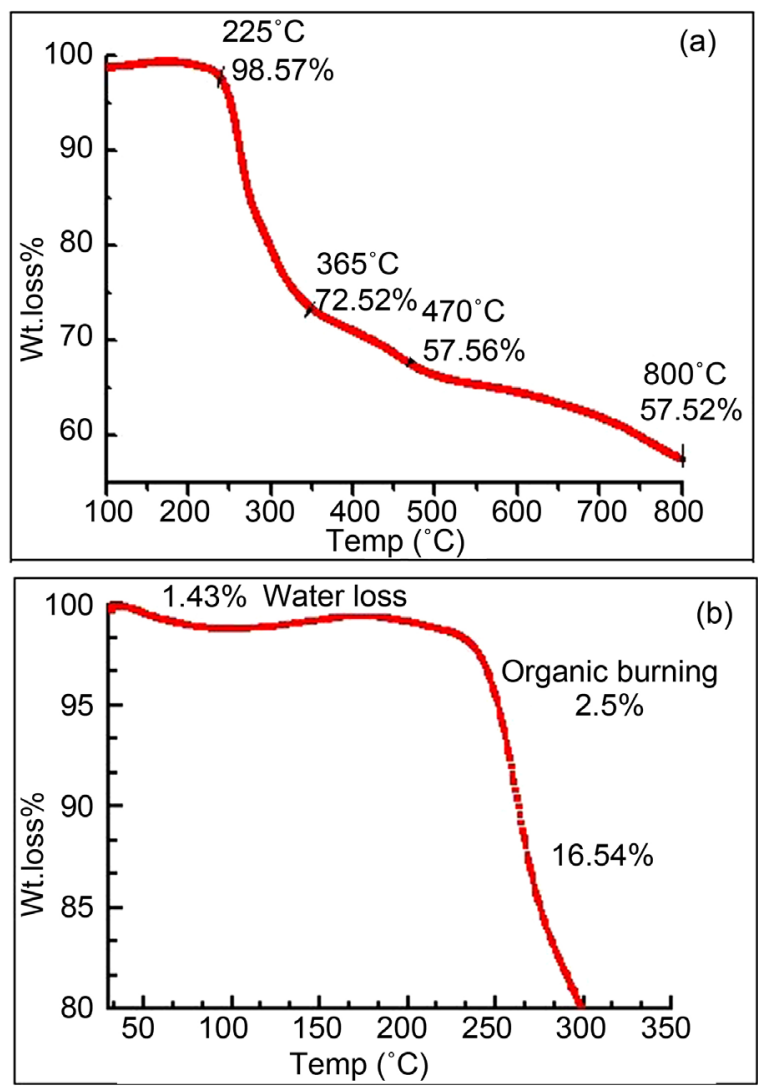

Figure 5. (a) The TGA graph of the green synthesized Ag-NPs up to $800^{\circ} \mathrm{C}$, (b) Enlarged TGA curve of powder Ag-NPs up to $300^{\circ} \mathrm{C}$. The experimental Setup was repeated thrice and no significant errors were noted.

room temperature $\left(30^{\circ} \mathrm{C}\right)$ to $800^{\circ} \mathrm{C}$ using TGA. A ceramic $\left(\mathrm{Al}_{2} \mathrm{O}_{3}\right)$ crucible was used for heating and measurements were carried out in $\mathrm{N}_{2}$ atmosphere at the heating rate of $10^{\circ} \mathrm{C} / \mathrm{min}$. TGA curve of powder Ag-NPs is more preciously shown in Figure 5(b) (up to $300^{\circ} \mathrm{C}$ ). It was found from TGA curve that dominant weight loss of the Ag-NPs occurred in the temperature range between $225^{\circ} \mathrm{C}$ to $300^{\circ} \mathrm{C}$. There was almost $1.43 \%$ weight loss below $225^{\circ} \mathrm{C}$ due to loss of water molecules present in biosynthesized Ag-NPs. Above $225^{\circ} \mathrm{C}$, there was $2.45 \%$ weight loss due to the burning of the organic constituents. In conclusions, TGA graph of biosynthesized Ag-NPs showed that the effective loss of weight $(20.31 \%)$ occurred up to $300^{\circ} \mathrm{C}$ temperature. Also, there was a steady weight loss occurred up to $800^{\circ} \mathrm{C}$ temperature. The total weight loss up to $800^{\circ} \mathrm{C}$ for Ag-NPs (Figure 5(a)) was about $42.48 \%$. The observed behaviour is most likely as a consequence of the surface desorption of phytochemicals surrounded in NPs. Thus, plant roots extract-stabilized Ag-NPs are accepted to be fabricated of molecules conscientious for the diminution of metal ions and stabilizing the particles in the mixture solution. The melting and boiling temperatures of smaller particles were observed less compare to the larger particles as explained by Kasthuri et al. [20].

\subsection{Stability of Ag-NPs}

The Zeta potential ( $\zeta$ ) of the biosynthesized Ag-NPs was found to be (-) $43.4 \mathrm{mV}$ in 
neutral $\mathrm{pH}$ background (Figure 6(a)). It concludes that $\mathrm{Ag}-\mathrm{NP}_{\mathrm{S}}$ are very stable. The large negative $\zeta$ value could be due to the capping of polyphenolic constituents present in the roots extract [21]. The negative nature of $\zeta$ prevented Ag-NPs from the agglomeration and made it good dispersion stability. The $\mathrm{pH}$ dependence of $\zeta$ value of biosynthesized Ag-NPs in aqueous environment is shown in (Figure 6(b)). Aqueous Ag-NPs suspension exhibited good stability $\zeta(-) 43.4 \mathrm{mV}$ at neutral $\mathrm{pH}$ whereas the same exhibited moderate stability between the $\mathrm{pH}$ ranges of $7-14$. The magnitude of $\zeta(-29.9$ $\mathrm{mV}$ ) at $\mathrm{pH} 14$ signified to a less stable NPs suspension compare to neutral medium. This report also suggested that smaller Ag-NPs were present at low $\mathrm{pH}(<5)$, since the less stability would be expected for small particles because of increased surface free energy [22].
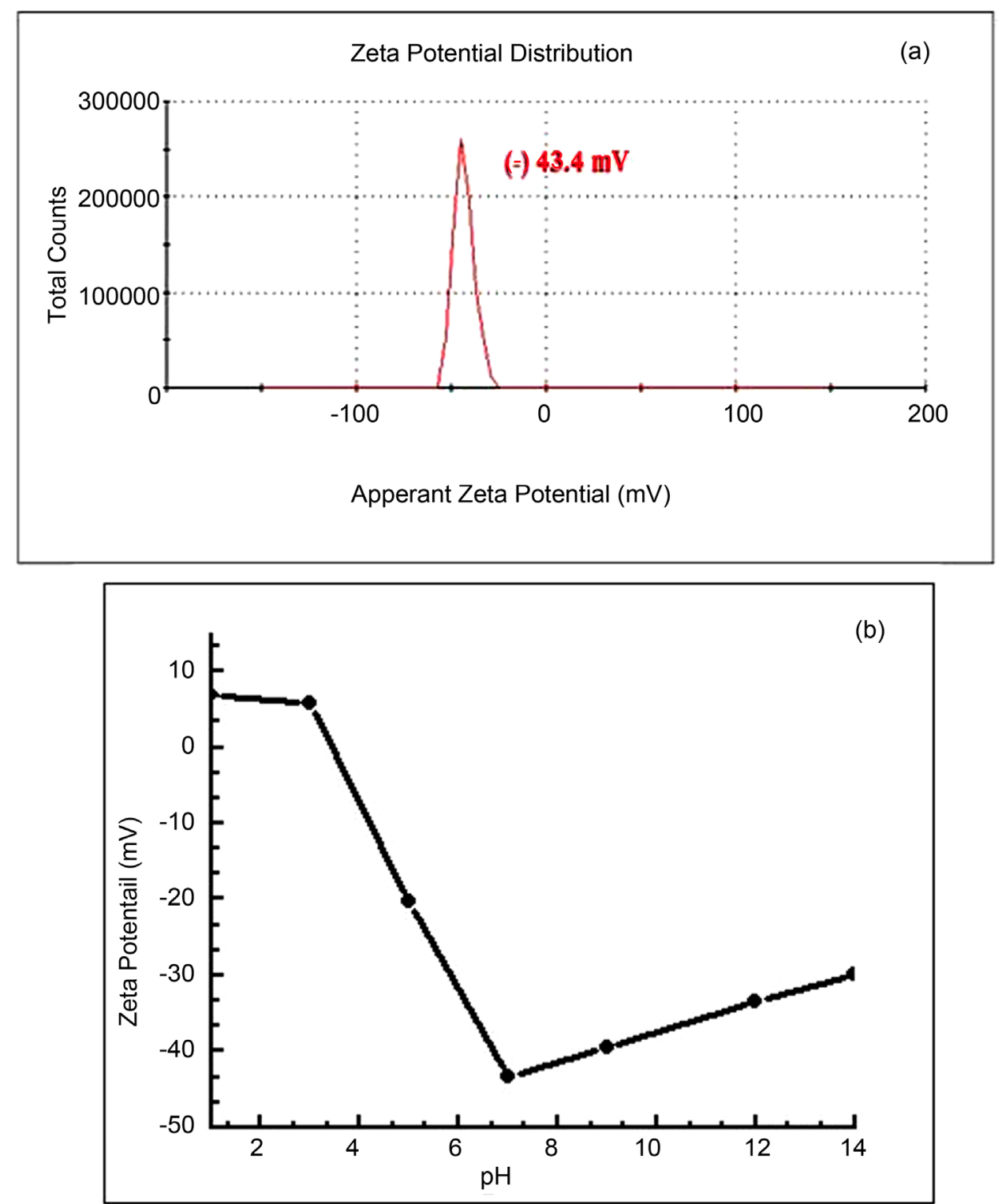

Figure 6. (a) Zeta Potential ( $\zeta$ ) curve of synthesized Ag-NPs in neutral pH environment and (b) $\mathrm{pH}$ dependence of $\zeta$ value of biosynthesized Ag-NPs in aqueous environment. The experimental setup was repeated thrice and the average with Standard Error of Zeta potential was presented. 


\subsection{Antioxidant Activity of Ag-NPs}

The anti-oxidative effect of green synthesized Ag-NPs on DPPH is thought to be due to their hydrogen donating capability [23]. As DPPH is a familiar as lipophilic radical, this readily accepts electron from the antioxidant materials and converts its colour from violet to yellow. At $517 \mathrm{~nm}$, the absorbance of the DPPH solution (i.e. the blank) was 0.501 . The reduction in absorbance of DPPH at $517 \mathrm{~nm}$ caused by the samples (Ag-NPs or ascorbic acid) was measured in triplicate after $10 \mathrm{~min}$ interval. The tested samples (Ag-NPs or ascorbic acid) showed very good activity when calculated using equation [1] and compared with the standard used (Table 1). There was a decrease in absorption at $517 \mathrm{~nm}$ signifying that the roots extract and Ag-NPs had hydrogen donating ability. From the above analysis, the samples (Ag-NPs or ascorbic acid) showed a concentration dependent radical scavenging capacity. This observation was further corroborated by calculating percentage inhibition for all the test samples (Ag-NPs or ascorbic acid). It was pragmatic that biosynthesized Ag-NPs exhibited moderate activity as free radical scavenger compared to the control. At $0.002 \mathrm{mg} / \mathrm{ml}$ concentration as-prepared Ag-NPs showed maximum antioxidant activity. The antioxidant activity of Ag-NPs using Gymnadenia orchidis Lindl roots extract may be due to the presence of some active phytochemical compounds in the plant roots.

\subsection{Photo-Catalytic Activity of Ag-NPs}

Photo-catalytic activity of green synthesized Ag-NPs on degradation of MB dye is demonstrated successfully (Figure 7(a)). The degradation of MB dye was carried out in the presence of Ag-NPs at different time interval in visible region under UV light irradiation. Firstly, the absorption peaks of $\mathrm{MB}$ dye solution at $663 \mathrm{~nm}$ were decreased regularly with the increase of the exposure time which indicates the photo-catalytic degradation of MB dye under UV light irradiation. The percentage of degradation efficiency of biosynthesized Ag-NPs was calculated using Equation (2) and tabulated in Table 2. Within $120 \mathrm{~min}$ the MB dye was degraded by $57.1 \%$ which concluded the fact that biosynthesized Ag-NPs were effective photo catalyst within small exposure time. The notable photo catalytic activity of biosynthesized Ag-NPs was mainly because of the presence of some facade proteins that surrounded the Ag-NPs [24]. Table 2 indicates the change of $\%$ of decolourization of MB dye with the exposure time of UV light irradiation, in presence of biosynthesized Ag-NPs. Figure 7(b) indicates the normalize

Table 1. Antioxidant activity study of as prepared Ag-NPs by DPPH assay.

\begin{tabular}{ccccc}
\hline $\begin{array}{c}\text { Concentration } \\
(\mathrm{mg} / \mathrm{mL}) \mathrm{Ag}-\mathrm{NPs}\end{array}$ & $\begin{array}{c}\text { Absorbance of } \\
\text { reaction mixture } \\
\text { with \% inhibition }\end{array}$ & Ascorbic & Acid & $\begin{array}{c}\text { Absorbance of } \\
\text { reaction mixture } \\
\text { with \% inhibition }\end{array}$ \\
\hline 0.001 & $0.398 \pm 0.04$ & $20.56 \pm 0.2$ & $0.105 \pm 0.03$ & $79.04 \pm 0.1$ \\
0.002 & $0.321 \pm 0.03$ & $35.93 \pm 0.1$ & $0.098 \pm 0.02$ & $80.44 \pm 0.2$ \\
0.003 & $0.348 \pm 0.01$ & $30.54 \pm 0.4$ & $0.117 \pm 0.04$ & $76.65 \pm 0.2$ \\
0.005 & $0.390 \pm 0.04$ & $22.16 \pm 0.2$ & $0.106 \pm 0.01$ & $78.84 \pm 0.4$ \\
\hline
\end{tabular}

Absorbance value from scavenging effect of standard control on DPPH at $517 \mathrm{~nm}$ was $0.501 \pm 0.04$. 
Table 2. Photo-catalytic activity study of Ag-NPs.

\begin{tabular}{cc}
\hline Exposure time (in Mins) & Amount of degradation of MB dye (in \%) \\
\hline 0 & 13.5 \\
5 & 28.7 \\
30 & 32.5 \\
60 & 42.3 \\
90 & 51.6 \\
120 & 57.1
\end{tabular}

Absorbance values of $10 \mu \mathrm{M} \mathrm{MB}$ dye solution react with Ag-NPs at $663 \mathrm{~nm}$ was $C_{0}=0.7472$.
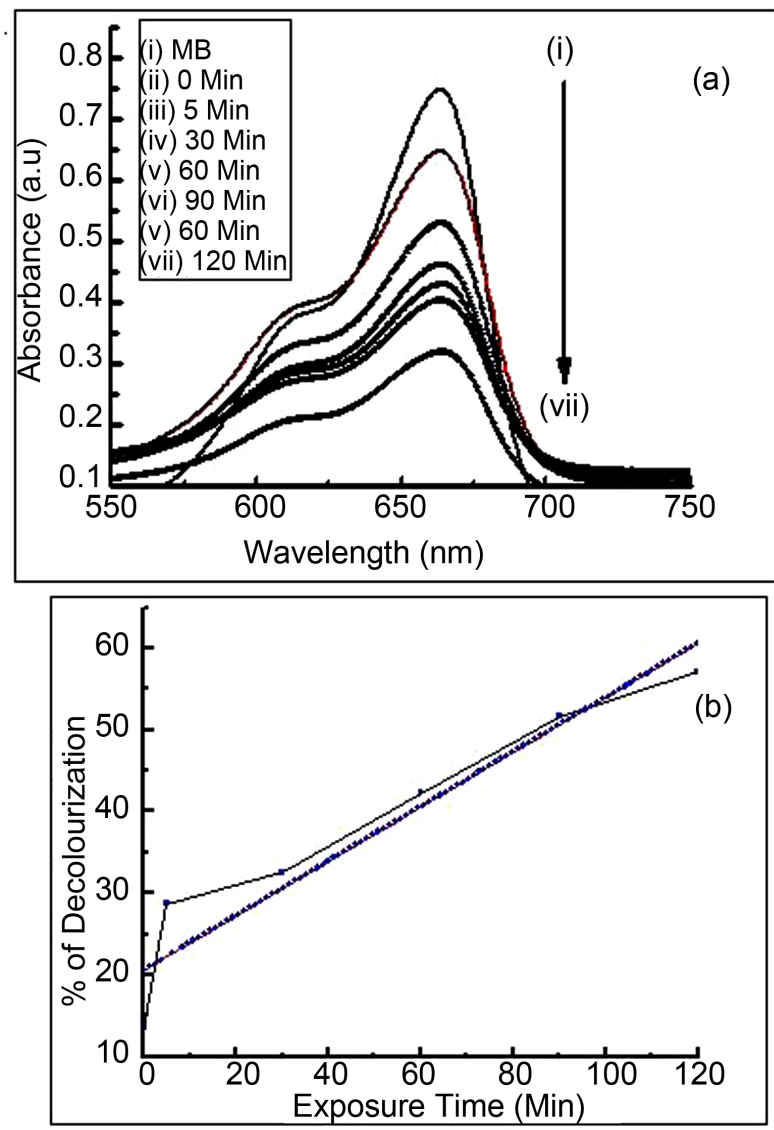

Figure 7. (a) Photocatalytic measurement of MB dye solution treated with the biosynthesized Ag-NPs. (b) Percentage of decomposition of $\mathrm{MB}$ dyes when treated with biosynthesized Ag-NPs at different functional time intervals. The blue dotted line is the mean curve of the experimental data. The experimental Setup was repeated thrice and no significant errors were noted.

graph of the data as stated in Table 2.

\subsection{Antibacterial Activity of Ag-NPs}

The diameters of the inhibition zones were measured against gram positive $S$. aureus bacterial growth. The experimental setup was repeated thrice and the average diameter 
of inhibition was given with standard error. Three different concentrations of biosynthesized Ag-NPs solutions viz., $25 \mu \mathrm{g} / \mathrm{ml}, 50 \mu \mathrm{g} / \mathrm{ml}$ and $100 \mu \mathrm{g} / \mathrm{ml}$ were used and the corresponding diameters of inhibition zones were determined as $(15 \pm 0.1),(16 \pm 0.3)$ and (18 \pm 0.2$) \mathrm{mm}$ respectively (Figure 8). As the concentration of Ag-NPs increased the inhibition zone of bacterial growth was also increased. This result concludes that the biosynthesized Ag-NPs possesses prominent antibacterial activity against $S$. aureus bacteria. It was earlier reported that the antibacterial effect of Ag-NPs was caused by the interaction of membrane of bacterial cell wall and Ag-NPs, hence ensuing in amplified bacterial membrane permeability and as a result, death of the bacteria [25].

\subsection{Probable Pathway of Ag-NPs Formation}

It was observed that the aqueous extract of powder root of Gymnadenia orchidis Lindl contains some polyphenols, proteins, terpenoids and carbohydrates etc. (data communicated). The probable pathway involved for the green synthesis of Ag-NPs may be explained by the presence of nitrate reductive protein (FTIR data) or polyphenols (Zeta potential value) in the root extract of Gymnadenia orchidis Lindl. It is assumed that the biosynthesis of Ag-NPs by Gymnadenia orchidis Lindlroots extract follows a similar bio-reduction pathway as shown in Figure 9. The protein present in the roots extract was seen capping on the surface of Ag-NPs. This was confirmed by FTIR spectra (Figure 4(a)) that clearly revealed the amide I and amide II bands at 1620 and 1388 $\mathrm{cm}^{-1}$ respectively. The peak at $1388 \mathrm{~cm}^{-1}$ confirmed also the presence of aromatic amine and nitro groups.

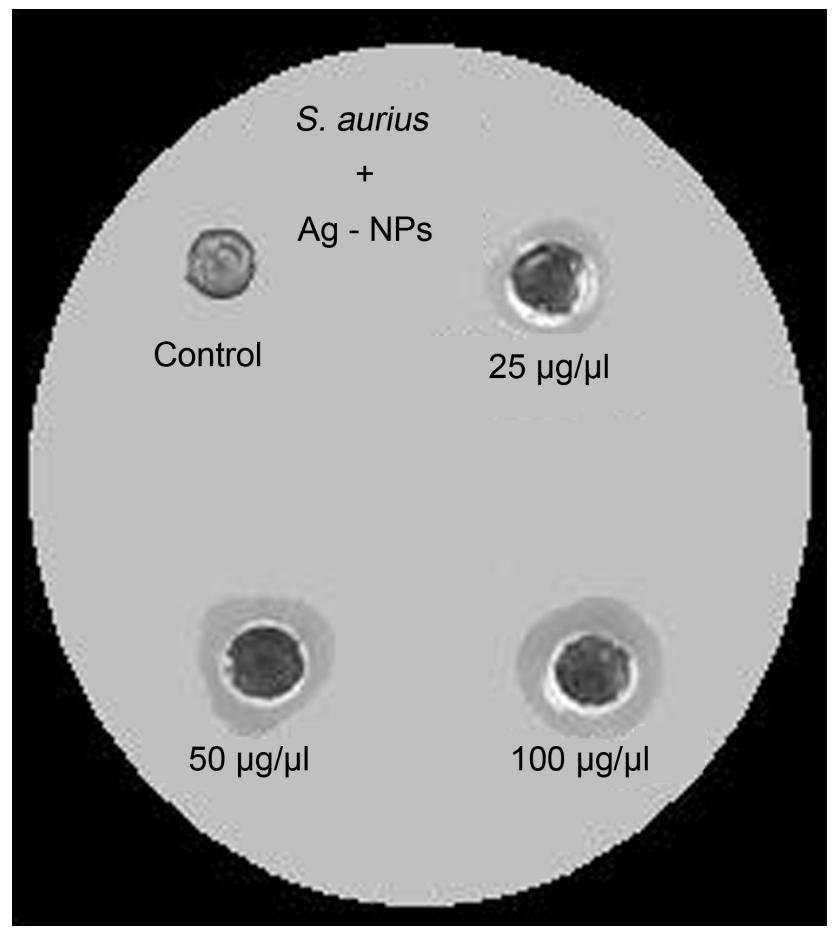

Figure 8. Antibacterial activity of the green synthesized AgNPs against $S$. aureus strain. The experimental setup was repeated thrice and the average with Standard Error of diameters of the inhibition zone was presented. 


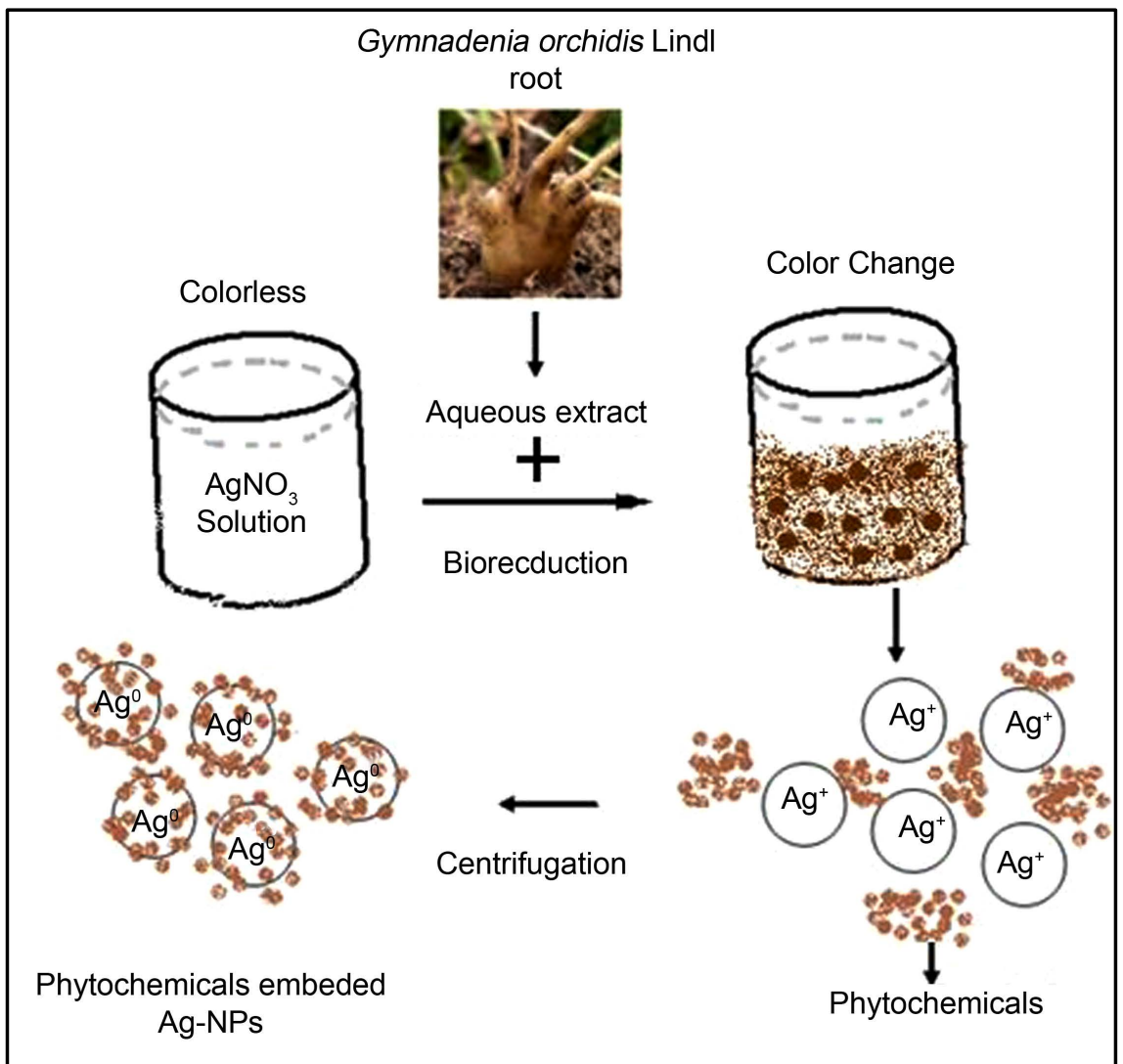

Figure 9. The probable pathway of Ag-NPs formation by the interaction of Gymnadenia orchidis Lindlroots extract and $\mathrm{AgNO}_{3}$ solution.

\section{Conclusion}

The green synthesis of Ag-NPs by the roots extract of Gymnadenia orchidis Lindl is a simplistic, rapid, ecological and low price technique at ambient temperature. This is a significant development for the formation of Ag-NPs as it allows better organization over their nanostructures. The presence of some phytochemicals like terpenoids, proteins and polyphenols in Gymnadenia orchidis Lindlroots extract may act as bio-reducer in the diminution process of $\mathrm{Ag}^{+}$to $\mathrm{Ag}^{\circ}$ and thus to $\mathrm{Ag}$-NPs. This study would provide a suitable utilization of the Gymnadenia orchidis Lindl as a hopeful agent in many biological applications. The photo-catalytic efficiency against MB dye molecules in short time exposure may be useful in technique involved for water purification systems and dye effluent treatment. The as-prepared Ag-NPs exhibit noticeably and considerably antibacterial cause that may be applicable as a prospective outcome for assorted biomedical entities.

\section{Conflict of Interests}

The authors declare that there is no conflict of interests regarding the publication of this paper.

\section{Acknowledgements}

The work was performed by the authors own support. The experimental facilities ob- 
tained from Biophysical Laboratory of Physics Department of Jadavpur University are gratefully acknowledged.

\section{References}

[1] Natarajan, K., Selvaraj, S. and Ramachandramurty, V. (2010) Microbial Production of Silver Nanoparticles. Digest Journal of Nanomaterials and Biostructures, 5, 135-140.

[2] Arunachalam, K.D., Annamalai, S.K. and Hari, S. (2013) One-Step Green Synthesis and Characterization of Leaf Extract-Mediated Biocompatible Silver and Gold Nanoparticles from Memecylon umbellatum. International Journal of Nanomedicine, 8, 1307-1315. https://doi.org/10.2147/IJN.S36670

[3] Show, S., Tamang, A., Chowdhury, T., Mandal, D. and Chattopadhyay, B.D. (2015) Bacterial (BKH1) Assisted Silica Nanoparticles from Silica Rich Substrates: A Facile and Green Approach for Biotechnological Applications. Colloids and Surfaces B: Biointerfaces, 126, 245-250. https://doi.org/10.1016/j.colsurfb.2014.12.039

[4] Guidelli, E.J., Ramos, A.P., Zaniquelli, M.E.D. and Baffa, O. (2011) Green Synthesis of Colloidal Silver Nanoparticles Using Natural Rubber Latex Extracted from Hevea brasiliensis. Spectrochimica Acta Part A: Molecular and Biomolecular Spectroscopy, 82, 140-145. https://doi.org/10.1016/j.saa.2011.07.024

[5] Philip, D. (2009) Biosynthesis of Au, Ag and Au-Ag Nanoparticles Using Edible Mushroom Extract. Spectrochimica Acta Part A: Molecular and Biomolecular Spectroscopy, 73, 374381. https://doi.org/10.1016/j.saa.2009.02.037

[6] Yilmaz, M., Turkdemir, H., Kilic, M.A., Bayram, E., Cicek, A. and Mete, A. (2011) Biosynthesis of Silver Nanoparticles Using Leaves of Stevia rebaudiana. Materials Chemistry and Physics, 130, 1195-1202. https://doi.org/10.1016/j.matchemphys.2011.08.068

[7] Vijayaraghavan, K., Nalini, S.P.K., Prakash, N.U. and Madhankumar, D. (2012) One Step Green Synthesis of Silver Nano/Microparticles Using Extracts of Trachyspermum ammi and Papaver somniferum. Colloids and Surfaces B: Biointerfaces, 94, 114-117. https://doi.org/10.1016/j.colsurfb.2012.01.026

[8] Vijayaraghavan, K., Nalini, S.P.K., Prakash, N.U. and Madhankumar, D. (2012) Biomimetic Synthesis of Silver Nanoparticles by Aqueous Extract of Syzygium aromaticum. Materials Letters, 75, 33-35. https://doi.org/10.1016/j.matlet.2012.01.083

[9] Singh, S., Saikia, J.P. and Buragohain, A.K. (2013) A Novel "Green” Synthesis of Colloidal Silver Nanoparticles (SNP) using Dillenia indica Fruit Extract. Colloids and Surfaces B: Biointerfaces, 102, 83-85. https://doi.org/10.1016/j.colsurfb.2012.08.012

[10] Tamulya, C., Hazarikaa, M., Borah, S.C., Das, M.R. and Boruah, M.P. (2013) In Situ Biosynthesis of Ag, $\mathrm{Au}$ and Bimetallic Nanoparticles Using Piper pedicellatum C.DC: Green Chemistry Approach. Colloids and Surfaces B: Biointerfaces, 102, 627-634. https://doi.org/10.1016/j.colsurfb.2012.09.007

[11] Umadevi, M., Bindhu, M.R. and Sathe, V.A. (2013) A Novel Synthesis of Malic Acid Capped Silver Nanoparticles Using Solanum lycopersicums Fruit Extract. Journal of Materials Science \& Technology, 29, 317-322. https://doi.org/10.1016/j.jmst.2013.02.002

[12] Miri, A., Sarani, M., Bazaz, M.R. and Darroudi, M. (2015) Plant-Mediated Biosynthesis of Silver Nanoparticles Using Prosopis farcta Extract and Its Antibacterial Properties. Spectrochimica Acta Part A, 141, 287-291. https://doi.org/10.1016/j.saa.2015.01.024

[13] Savage, N. and Mamadou, S.D. (2005) Nanomaterials and Water Purification: Opportunities and Challenges. Journal of Nanoparticle Research, 7, 331-342. https://doi.org/10.1007/s11051-005-7523-5

[14] Yolaa, M.L., Erenb, T., Atar, N. and Wang, S. (2014) Adsorptive and Photocatalytic Removal of Reactive Dyes by Silver Nanoparticle-Colemanite Ore Waste. Chemical Engineering 
Journal, 242, 333-340. https://doi.org/10.1016/j.cej.2013.12.086

[15] Noginov, M.A., Zhu, G., Bahoura, M., Adegoke, J., Small, C. and Ritzo, B.A. (2007) The Effect of Gain and Absorption on Surface Plasmons in Metal Nanoparticles. Applied Physics B, 86, 455-460. https://doi.org/10.1007/s00340-006-2401-0

[16] Tripathi, R.M., Kumar, A., Shrivastav, P., Singh, B. and Shrivastav, R. (2013) Catalytic Activity of Biogenic Silver Nanoparticles Synthesized by Ficus panda Leaf Extract. Journal of Molecular Catalysis B: Enzymatic, 96, 75-80. https://doi.org/10.1016/j.molcatb.2013.06.018

[17] Molyneux, P. (2004) The Use of the Stable Free Radical Diphenylpicrylhydrazyl (DPPH) for Estimating Antioxidant Activity. Journal of Science and Technology, 26, 211-219.

[18] Gengan, R.M., Anand, K., Phulukdaree, A. and Chuturgoon, A. (2013) A549 Lung Cell Line Activity of Biosynthesized Silver Nanoparticles Using Albizia adianthifolia Leaf. Colloids and Surfaces B: Biointerfaces, 105, 87-91. https://doi.org/10.1016/j.colsurfb.2012.12.044

[19] Mulvaney, P. (1996) Surface Plasmon Spectroscopy of Nanosized Metal Particles. Langmuir, 12, 788-800. https://doi.org/10.1021/la9502711

[20] Kasthuri, J., Kathiravan, K. and Rajendiran, N. (2009) Phyllanthin-Assisted Biosynthesis of Silver and Gold Nanoparticles: A Novel Biological Approach. Journal of Nanoparticle Research, 11, 1075-1085. https://doi.org/10.1007/s11051-008-9494-9

[21] Sathishkumar, M., Sneha, K., Won, S.W., Cho, C.W., Kimand, S. and Yun, Y.S. (2009) Cinnamon zeylanicum Bark Extract and Powder Mediated Green Synthesis of Nano-Crystalline Silver Particles and Its Bactericidal Activity. Colloids and Surfaces B: Biointerfaces, 73, 332-338. https://doi.org/10.1016/j.colsurfb.2009.06.005

[22] Pandey, S., Mewada, A., Thakur, M., Shinde, S., Shah, R., Oza, G. and Sharon, M. (2013) Rapid Biosynthesis of Silver Nanoparticles by Exploiting the Reducing Potential of Trapabispinosa Peel Extract. Journal of Nanoscience, 10, 516357-516373.

[23] Pettibone, J.B., Elzey, S. and Grassian, V.H. (2008) An Integrated Approach toward Understanding the Environmental Fate, Transport, Toxicity and Health Hazards of Nanomaterials. In: Grassian, V.H., Ed., Nanoscience and Nanotechnology. Environmental and Health Impacts, Wiley, Hoboken, 47-50. https://doi.org/10.1002/9780470396612.ch3

[24] Baumann, J., Wurn, G. and Bruchlausen, F.V. (1979) Prostaglandin, Synthetase Inhibiting $\mathrm{O}_{2}{ }^{-}$Radical Scavenging Properties of Some Flavonoids and Related Phenolic Compounds. Arc Pharmacol, 307, R1-R77.

[25] Jain, N., Bhargava, A. and Panwar, J. (2013) Enhanced Photocatalytic Degradation of Methylene Blue Using Biologically Synthesized "Protein-Capped" ZnO Nanoparticles. The Chemical Engineering Journal, 13, 01563-01568. 
Submit or recommend next manuscript to SCIRP and we will provide best service for you:

Accepting pre-submission inquiries through Email, Facebook, LinkedIn, Twitter, etc. A wide selection of journals (inclusive of 9 subjects, more than 200 journals) Providing 24-hour high-quality service

User-friendly online submission system

Fair and swift peer-review system

Efficient typesetting and proofreading procedure

Display of the result of downloads and visits, as well as the number of cited articles Maximum dissemination of your research work

Submit your manuscript at: http://papersubmission.scirp.org/

Or contact jbnb@scirp.org 